\title{
Optimal Fear of Floating: The Role of Currency Mismatches and Fiscal Constraints
}

\author{
Eduardo J. J. Ganapolsky ${ }^{12}$ \\ Federal Reserve Bank of Atlanta
}

\begin{abstract}
Evidence suggests that developing countries are much more concerned with stabilizing the nominal exchange rate than developed countries. This paper presents a model to explain this observation, based on the hypotheses that both interventions and depreciations are costly. Interventions are costly because they generate a financial need in a fiscally constrained government that relies solely on distortionary taxes. Depreciations are costly because the country, in particular its financial sector, is exposed to a currency mismatch between its assets and its liabilities that is not effectively hedged. The results suggest that the amount of intervention will depend on the degree of currency mismatch between assets and liabilities, the elasticity of money demand, and the relative size of the financial system. It would be expected that countries with a high degree of currency mismatch and large financial sectors would intervene heavily in foreign exchange markets, as long as the money demand is not too sensitive to the nominal interest rate.
\end{abstract}

JEL Classification: E5, F3, F41

Keywords: exchange rates, floating, currency mismatch, fiscal constraint, optimal policy

\footnotetext{
${ }^{1}$ I am indebted to Carlos Végh for many discussions and his helpful suggestions. I would also like to thank Hal Cole, Arnold Harberger, Amartya Lahiri, Monika Piazzesi, Martin Schneider, Aaron Tornell and seminar participants at UCLA, CEMA, FRB of Kansas City and FRB of Atlanta for their useful comments. 2 Mail address: 1000 Peachtree Street N.E., Atlanta, GA, 30305. Phone: (404) 498 8785. Fax: (404) 498 8058. E-mail address: eduardo.ganapolsky@atl.frb.org
} 


\section{Optimal Fear of Floating: The Role of Currency Mismatches and Fiscal Constraints}

\section{Introduction}

Evidence suggests that developing countries are much more concerned with stabilizing the nominal exchange rate than developed countries. Some recent papers show not only that nominal exchange rates are less volatile in developing countries, but also that their international reserves and domestic interest rates are significantly more volatile (Calvo and Reinhart (2002), (2000), Hausmann, Panizza, and Stein (2001), Levy-Yeyati and Sturzenegger (2002)). Why do we observe this fear of floating in emerging markets? What is the underlying rationale for this behavior?

Assuming sluggishness in price adjustment, some papers essay an answer to those questions (Lahiri and Végh (2001), Parrado and Velasco (2002), Caballero and Krishnamurthy (2001)). Nobody, however, has thus far been able to provide an explanation for the whole range of exchange rate policies that is observed in the real world. The spectrum goes from countries that fully intervene to keep the exchange rate stable to those that engage in clean flotation -- not intervening at all -- with many others intervening to various degrees and thus lying somewhere in between these two extremes.

This work provides a model with flexible prices that introduces a new channel through which the fear of floating is generated. It departs from the previous research in an important dimension; fears will come from nominal, as supposed to real, exchange rate volatility. Also, the model is able to explain the whole range of observed policies. The trade-off proposed in the paper is driven by two facts that proved to be crucial in recent financial crises: emerging market countries face fiscal restrictions during turbulent times, and they tend to have a mismatch in the currency denomination of their assets and their liabilities. These features make both interventions and depreciations costly. Thus, faced with these costs policymakers have to choose the optimal policy mix, such that the costs are minimized. 
This paper models intervention and depreciation costs explicitly. Having exogenous costs may hide differences across countries that could be essential explain the diversity of policy responses. Therefore, making the costs endogenous will allow us to determine how costs are related to the structure of the economy.

The intervention cost is based on the idea that governments have to use scarce resources to intervene in the exchange rate market. Interventions consume reserves, which generates a financial need. If there is nothing but distortionary instruments to raise resources, then the government will be reducing the welfare of the society to finance the intervention. ${ }^{1}$ This idea is very general and would work for any distortionary tax or subsidy. However, to make the model more tractable and closer to the emerging markets' reality, it is assumed that the government finances the intervention through the inflation tax. $^{2}$

Obviously, the size of this welfare cost depends on structural parameters, such as, for instance, the elasticity of money demand. In general, countries with a long history of inflation have a very elastic money demand. Therefore, raising funds through a perfectly anticipated inflation tax to finance the intervention will be more "expensive" for these countries than for those without an inflationary tradition.

The cost of nominal exchange rate volatility comes from the exposure of the economy to the exchange rate risk. ${ }^{3}$ This paper takes the currency mismatch (liabilities in foreign currency are greater than assets in the same currency) as given and assumes that the banking sector is exposed to that exchange rate risk. That is, banks borrow abroad in foreign currency and lend domestically, both in domestic and foreign currency. This unhedged position in banks' balance-sheets causes discrete losses in the event of an unexpected depreciation, which, if big enough, could send a bank into bankruptcy. When

\footnotetext{
${ }^{1}$ If the government can raise lump-sum taxes or if it can cut unproductive expenditures, financing the intervention would not generate any social cost, which are the usual assumptions made in the literature. ${ }^{2}$ The same would happen if it finances the intervention through the introduction of any other distortionary tax, like a tax on the financial system. This kind of tax was used in Brazil (1999) and Argentina (2001) due to the constraints that the fiscal authorities faced at those times.

${ }^{3}$ The literature shows that emerging markets' firms and banks borrow extensively from abroad, and that they do not completely hedge the exchange rate risk (Burnside, Eichenbaum, and Rebelo (1999); Hausmann et al. (2001)).
} 
some banks disappear from the scene, there is a credit crunch in the economy, undermining its production capacity, and therefore reducing its output. ${ }^{45}$

Thus, the depreciation cost also depends on structural parameters, in this case the currency mismatch in the financial system. Countries that do not have the possibility of hedging their liabilities denominated in foreign currency will suffer more from discrete depreciations.

Based on these intervention and depreciation costs, the model is able to rationalize as the outcome of an optimal policy decision, the observation that emerging markets end up with higher inflation rates and lower fluctuations in the nominal exchange rate. The results suggest that the amount of intervention depends on the degree of currency mismatch, the elasticity of money demand, and the relative size of the financial system. Estimations of a stylized econometric model support the effect of these variables on the variability of the exchange rate. The correlation between variability and the mismatch is negative; the correlation between variability and elasticity is positive; the correlation between variability and size is negative; and all of them are highly significant across most specifications.

How much to fear floating will depend on each country's circumstances at a given point in time. This has strong policy implications. Countries with highly elastic money demand would refrain from intervening too much in the foreign exchange market if they are not able to undertake a fiscal adjustment. For them, it would be better to raise revenues with an unexpected depreciation than relying on a perfectly anticipated future inflation tax. On the other hand, countries with a high degree of currency mismatch

\footnotetext{
${ }^{4}$ This mechanism resembles the "lending channel" introduced by Bernanke and Gertler, but here, it is in other clothes. The shortage of credit comes from the fall in the supply of loans, which is produced by the "default" of some banks. In the traditional case, it comes from an increase in the lending spread, which is produced by the higher external finance premium that is paid by the financial institutions.

${ }^{5}$ The effects generated by depreciations or appreciations could be interpreted as if they were not symmetric. If a depreciation occurs, the banks would suffer a loss. If the loss is big enough, those banks could go bankrupt, and the banking system might disappear or be severely downsized. The effects on the economy would be quite straightforward, especially in developing countries, where the banking system has a key role of channeling funds from lenders to borrowers. On the other hand, if an appreciation occurs, the banks would make a nominal gain that would increase their net worth. But in this case, the once-and-for-all gain would not generate any major change or disruption in the economic system.
} 
would play tough to stabilize the value of the currency, even at expense of higher future inflation.

The paper is organized as follows. Section 2 shows some stylized facts. Section 3 presents the model and describes the margins through which the model operates. Section 4 analyzes the response of the modeled economy to a negative monetary shock and gives the rationale for the fear of floating. Finally, Section 5 concludes and points out directions for future research.

\section{Stylized facts}

The term "fear of floating" was coined by Calvo and Reinhart (2002). In this paper, they study the volatility of the nominal exchange rate, international reserves, interest rates and terms of trade for 154 exchange rate regimes. Figure 1 is constructed using the results of the paper mentioned above for the countries that self-declared having a floating exchange rate regime. Theoretically, it has to be that the probability of having a big change in the nominal exchange rate is high, and the probability of having a big change in the stock of international reserves is low, since the authorities should not intervene in the foreign exchange market. Nevertheless, the empirical findings illustrated in Figure 1 go exactly in the opposite direction. These "floaters" have low probabilities of (big) changes in the nominal exchange rate and high probabilities of (big) changes in the stock of international reserves, which suggests that monetary authorities are deliberately intervening to keep the price of the currency stable.

Comparing emerging with developed countries, the literature agrees on the following facts: ${ }^{6}$

(i) Nominal exchange rate volatility is lower.

(ii) International reserves volatility is higher.

(iii) Interest rate volatility is higher.

Table 1 provides some additional evidence on the low variability of exchange rates relative to the variability of reserves. The reported statistics clearly show that on average, emerging markets have less relative nominal exchange rate volatility than developed

\footnotetext{
${ }^{6}$ See for example, Calvo and Reinhart (2002) and Hausmann et al. (2001).
} 
countries. $^{7}$ They also confirm the very well known fact that emerging markets tend to have higher inflation than developed countries.

So, what is different about emerging markets? The following facts may help to answer this question: ${ }^{8}$

(iv) They hold a higher stock of international reserves (in relative terms).

(v) They have bigger and less hedged currency mismatches. They mainly borrow in foreign currency (and through the banking system).

(vi) They have a lower degree of monetization.

In Table 1 there is extra support for the facts (v) and (vi). The third column shows a measure of the currency mismatch in the financial system for all the countries in the sample. ${ }^{9}$ This measure is the ratio between liabilities and assets in foreign currency; hence, a ratio bigger than one would indicate that the financial system is exposed to depreciations. ${ }^{10}$ In fact, that exposition could be hedged if there exist enough financial contracts to do so. It is not easy to quantify the actual amount of hedging, but it would be safe to say that the higher the level of development is, the broader the financial markets will be. Therefore, emerging markets find it more difficult to insure against exchange rate risk than developed countries. Beyond this observation, the average ratio in emerging market is well above one; they hold 1.7 times more liabilities than assets in foreign currency.

It is apparent that the ratio of money-to-GDP (i.e. the so called "monetization") is substantially smaller in emerging markets. On average, the degree of monetization in these economies is just $8 \%$, which is below the $30 \%$ or $20 \%$ for Japan and the US, respectively. From a fiscal perspective, a lower degree of monetization means that the base for an "inflation tax" is smaller, implying a higher tax rate in order to collect the same amount of revenues.

\footnotetext{
${ }^{7}$ This is also true for most of the individual cases that are reported in the table.

${ }^{8}$ As documented in Burnside et al. (1999) and Hausmann et al. (2001).

${ }^{9}$ Throughout the paper the terms financial system and banking system will be used interchangeably.

${ }^{10}$ From the point of view of this chapter, it is not appropriate to talk just about dollarization, because it does not convey any notion of "exposure" to exchange rate risk. What matter is if there is "net" liabilities in foreign currency or not.

It is also true that this ratio does not capture the whole degree of exposure. It could happen that a bank with zero mismatch suffer from a depreciation when some of their debtor are exposed to the mismatch, and therefore the quality of the portfolio deteriorates.
} 
Also, it could be noted that in most crises:

(vii) The International Monetary Fund (IMF) and other multilateral organizations provided emergency loans. ${ }^{11}$

(viii) It was difficult to do a fiscal adjustment that falls directly on consumers or productive firms.

The first point suggests that assuming emerging markets suffer from credit rationing at the time of a crisis could be misleading, because they may have access to foreign loans, especially when they need those funds to defend the currency. On the other hand, the second observation suggests that in a crisis, governments should rely more on other sources of revenues, rather than on traditional taxes. The inflation tax was the preferred alternative for several emerging markets.

To provide some support to the model outlined in the introduction, Tables 2 and 3 present some estimations about the role of the new channels in generating fear of floating. The purpose of this exercise is to see how the dependent variable, the percentage change in the exchange rate per unit of percentage change in reserves, ${ }^{12}$ is affected by the factors that are proposed as the drivers of the (rational) fear. The method of estimation is simply an ordinary least square (OLS) regression on the stacked time series for the 15 countries. Estimated coefficients are restricted to be the same across countries, and the disturbance term for each country is assumed to be independent among countries, which stands in line with the assumptions of the theoretical model. ${ }^{13}$

The estimated equations are:

$$
\begin{aligned}
& z_{i t}=\phi+\gamma x_{i t}+\eta o_{i t}+\mu_{i t}, \\
& z_{i t}=\phi+v F_{i}+\gamma x_{i t}+\eta o_{i t}+\mu_{i t},
\end{aligned}
$$

where $z_{i t}$ is the ratio between the percentage change in the exchange rate and the percentage change of international reserves, $x_{i t}$ is the vector of variables relevant for the

\footnotetext{
${ }^{11}$ Recent examples of this fact are the loans given by the IMF to Brazil and Uruguay in 2002, and to Argentina and Turkey in 2001.

${ }^{12}$ Which can be thought as the inverse of the "elasticity of intervention".

${ }^{13}$ In the model, changes in nominal exchange rates are driven by a monetary shock, which is a reduction in money demand for the domestic currency. Decisions about the amount of real balances depend on some domestic variables, which are in principle, unconnected among different countries. Moreover, if policymakers have the same objective function across countries, there would not be any difference in the policy response regarding to the same set of variables.
} 
model, $o_{i t}$ is the vector of some control variables, $\mu_{i t}$ is the disturbance term, and $F_{i}$ is the vector of dummies for each country.

The $x$ vector includes the currency mismatch ratio, the ratio of fiscal surplus over GDP (as indicative of the degree of flexibility on the fiscal side), past inflation and monetization (as proxies of the money demand elasticity), past growth rate (as a proxy of the productivity of the economy), and an index number to measure the real stock of banking credit (in some specifications, an interaction term between the currency mismatch and banking credit is introduced). The $o$ vector includes the real exchange rate and two dummy variables, one for Latin America and other for East Asia.

Interestingly, the fixed effects in Equation (2) turned out to be non-significant for most of the countries, which suggests there is nothing specifically related to each country that might explain the fear of floating. The signs and levels of significance of the reported variables remained roughly the same.

The results show that the currency mismatch has a negative impact on exchange rate changes, which is statistically significant across different specifications. ${ }^{14}$ The fiscal variable has a negative sign and it is very significative in all specifications. This suggests that when the fiscal budget is in deficit, the countries in the sample tend to float more than when it is in surplus. Regarding to the proxies of money demand elasticity, they show a positive relationship with the dependent variable, which are also statistically significant for the various specifications. The more elastic the money demand is (high past inflation or low degree of monetization) the greater are the relative changes in nominal exchange rate going to be. The stock of banking credit always has a negative effect on the dependent variable, either when it is considered alone or in the interaction term, and it shows high significance levels throughout the models.

On the side of the controls, the real exchange rate is related with the changes in nominal exchange rate in a negative way. An appreciated real exchange rate will lead to nominal depreciations, and vice versa.

\footnotetext{
${ }^{14}$ This result agree with Hausmann et al. (2001). They find that higher degrees of dollarization (for the whole economy) lead to lower flexibility of the exchange rate.
} 


\section{The model}

Consider a small open economy (SOE) inhabited by a large number of identical individuals, with a banking sector and a government, where all the agents have perfect foresight.

In this economy, there exists just one tradable good, $c_{t}$, and the law of one price holds. Assume that the price of the good in the rest of the world, $P^{*}$, is given and equal to one. Therefore, the domestic price of consumption good, $P_{t}$, will be equal to the nominal exchange rate, $E_{t}$.

Capital is perfectly mobile across countries. All these assumptions together imply the following interest parity condition:

$$
i_{t}=r+\varepsilon_{t},
$$

where $i_{t}$ is the domestic nominal interest rate, $r$ is the real interest rate determined in the international capital markets, which is exogenously given and constant, and $\varepsilon_{t}$ is the depreciation rate of the domestic currency.

The model departs from the standard SOE model in two ways. First, the banking sector is composed by a continuum of banks that differ in their efficiency level, which have an unhedged position in liabilities in foreign currency. Second, the government cannot rely on lump-sum taxation.

\subsection{Households}

The infinitely lived representative household derives utility from consumption of the only tradable good, according to the following utility function:

$$
U=\int_{0}^{\infty} \log \left(c_{t}\right) e^{-\beta t} d t,
$$

where $U$ is the lifetime welfare of the household, and $\beta$ is the rate of intertemporal preference.

The household holds two different assets, money and an internationally traded bond. Its financial wealth in real terms is given by:

$$
a_{t}=m_{t}+b_{t},
$$


where $a_{t}$ is the financial wealth in real terms at time $t, m_{t}$ is the real amount of money, and $b_{t}$ is the real quantity of the internationally traded bond held by the household.

It also borrows from the bank to be able to produce the consumption good. At each point in time it receives the return on its financial assets, produces, pays the cost of the loans, consumes, receives transfers from the government and the profits made by the banks, and it wastes resources as a consequence of the opportunity cost of the money holdings and the cost of making transactions. The financial wealth evolves over time according to the following law of motion:

$$
\dot{a}=r a_{t}+y_{t}-r l_{t}^{A}-c_{t}+\tau_{t}+d_{t}^{A}-i_{t} m_{t}-v\left(m_{t}\right),
$$

where $\dot{a}$ is the instantaneous change in the financial wealth, $y_{t}$ is output, $l_{t}^{A}$ is the aggregate stock of loans that the household borrows, $\tau_{t}$ is a lump-sum transfer, $d_{t}^{A}$ are aggregate dividends received from the banks, and $v\left(m_{t}\right)$ are transaction costs.

The intertemporal constraint is obtained by integrating forward the expression (6):

$$
a_{0}+\int_{0}^{\infty}\left(y_{t}-r l_{t}^{A}+\tau_{t}+d_{t}^{A}\right) e^{-r t} d t=\int_{0}^{\infty}\left[c_{t}+i_{t} m_{t}+v\left(m_{t}\right)\right] e^{-r t} d t
$$

where $a_{0}$ is the initial stock of financial wealth.

Output is produced using bank loans as the only input, according to the following production function: ${ }^{15}$

$$
y_{t}=\Lambda l_{t}^{A},
$$

where $\Lambda$ is an exogenous parameter that determines the productivity of the bank loans.

It is assumed that the exchange process is costly in this economy, and this cost takes the form of a real resource loss. The household can reduce the cost by using money in its transactions. The transaction technology is characterized by:

$$
\begin{array}{ll}
v\left(m_{t}\right)>0 ; v^{\prime} \leq 0 ; v^{\prime \prime}>0 ; \\
v^{\prime}=0 \quad \text { for } 0<m<\infty .
\end{array}
$$

This means that transaction costs are reduced by holding more real balances, but there exists a satiation point.

\footnotetext{
${ }^{15}$ Bank loans in domestic currency and in foreign currency are assumed to be perfect substitutes in production.
} 
Hence, the household's problem is to maximize lifetime utility (4) subject to the intertemporal budget constraint (7), and the production function (8). The household must choose the optimal time paths of consumption, real balances and loans, $\left\{c_{t}, m_{t}, l_{t}^{A}\right\}_{0}^{\infty}$.

Denote by $\lambda$ the Lagrange multiplier associated with the intertemporal budget constraint, which could be interpreted as the marginal value of the household's financial wealth. Therefore, the first order conditions (FOCs) of this problem are: ${ }^{16}$

$$
\begin{aligned}
& \frac{1}{c_{t}}=\lambda \\
& i_{t}=-v\left(m_{t}\right) \\
& \lambda=r,
\end{aligned}
$$

which in turn imply:

$$
\begin{aligned}
& c=\frac{1}{\lambda} \\
& m_{t}^{d}=m\left(i_{t}\right) ; \quad m^{\prime}<0 \\
& l_{t}^{A d}=l^{\mathrm{A}} .
\end{aligned}
$$

Equation (12) implies that the path of consumption would be flat along the time. Equation (13) defines the real money demand as a function of the nominal interest rate, $i_{t}$. Finally, equation (14) reflects the equilibrium in the credit market.

\subsection{Banks}

The economy has a continuum of banks indexed by $n$, which are uniformly distributed over the interval $[0,1]$.

\subsubsection{The individual bank}

Each bank gives a real amount of loans, $l$, to the household, which will be used for productive purposes. A proportion $\alpha$ of those loans are denominated in the domestic

\footnotetext{
${ }^{16}$ Given the nature of the shock that will be analyzed later, to introduce stationarity into the model it would be enough to assume $r=\beta$.

It is assumed also that $r=\Lambda$, which means that the productivity in the rest of the world and in the domestic economy are the same.
} 
currency (pesos) at the exchange rate available at the time of the contract, and the rest, 1 $\alpha$, in the foreign currency (dollars). It is assumed that $\alpha$ belongs to the interval $[0,1)$.

The bank finances those loans by borrowing in dollars in the international capital markets. However, the amount that the bank needs to borrow to produce a given quantity of loans would depend on its efficiency, measured by $n$. That means, it would ask $n l$ from the external lenders. Thus, the n-bank's balance-sheet in real terms is:

$$
\alpha \cdot \bar{E} / E_{t} l_{t}+(1-\alpha) l_{t}=n l_{t}+w_{t},
$$

where $E$ is the nominal exchange rate at the time of the loan, $E_{t}$ is the nominal exchange rate at time $t$, and $w_{t}$ is the net worth of the bank at time $t$, which is given by:

$$
w_{t} \equiv\left[1-n-\alpha\left(1-\bar{E} / E_{t}\right)\right] l_{t} .
$$

What matters for having a real effect coming from a nominal depreciation is the currency mismatch that the bank has, not just the degree of dollarization of its liabilities. ${ }^{17}$ The currency mismatch in the n-bank, $\theta(n)$, according to the definition given in Section 2 is:

$$
\theta(n) \equiv \frac{n l}{(1-\alpha) l}=\frac{n}{1-\alpha} .
$$

Therefore, $\theta$ could take any value in the interval $[0,+\infty)$. In accordance with equation (17) the n-bank would be exposed to depreciations when $n>1-\alpha$. The higher the proportion the banks lend in pesos, higher $\alpha$, and the lower the efficiency of the bank, higher $n$, the more uncovered would the position of the bank be.

In their activity, banks charge the borrowers with the same real interest rate they pay in the international capital markets, $r$, and they distribute all the results as dividends to the household, $d_{t}$. Thus, the n-bank flow constraint is:

$$
\dot{w}=r w_{t}-d_{t}=0 .
$$

The value of the n-bank is defined as the present value of the future flow of dividends, which is given by:

$$
V_{0}(n)=\int_{0}^{\infty} d_{t} e^{-r t} d t
$$

When $E_{t}$ is constant from $t=0$ onwards, equation (19) boils down to:

\footnotetext{
${ }^{17}$ In the case in which the bank has fully hedged its liabilities, both nominal assets and nominal liabilities will increase when a nominal depreciation occurs, and no real effect would arise.
} 


$$
V_{0}(n)=[1-n-\alpha(1-\bar{E} / E)] l .
$$

It is assumed that banks need to have a non-negative value to operate. Banks with a strictly negative value, $V_{0}(n)<0$, will default and disappear from the system. The marginal bank $n^{*}$, that is the one with zero-value, will have a level of efficiency given by:

$$
V_{0}\left(n^{*}\right)=0 \text {. }
$$

Equation (21) implies that $n^{*}$ is:

$$
n^{*}=1-\alpha(1-\bar{E} / E) .
$$

When the nominal exchange rate at the time of the loan contract and the current exchange rate are the same, $n^{*}$ is one, and there are no defaults since $V_{0}(n) \geq 0$ for all $n$. But, when the nominal exchange rate depreciates, $n^{*}$ is less than one, and all the banks in the interval $\left(n^{*}, 1\right]$ will default. In this case, all those banks stop lending and collecting their revenues from the household, and they also stop borrowing and paying their obligations in the international capital markets.

\subsubsection{The financial system}

The financial system is the aggregation of all the banks. The amount of dividends distributed by the whole sector at each point in time, $d_{t}^{A}$, is:

$$
d_{t}^{A}=\int_{0}^{n^{*}} d_{t}(x) d x=r w^{A}
$$

where $w^{A}$ is the net worth of the financial system, which is given by:

$$
w^{A}=\left\{\left[1-n^{*} / 2-\alpha(1-\bar{E} / E)\right] l\right\} n^{*} .
$$

The term inside the braces is the average net worth in the system. The second term inside the square brackets represents the average efficiency cost of the banking sector, and the third term reflects the exposure to exchange rate depreciations.

The value of the financial system is:

$$
V_{0}^{A}=\int_{0}^{n^{*}} V_{0}(x) d x=\left[1-n^{*} / 2-\alpha(1-\bar{E} / E)\right] n^{*} l .
$$

It would also be useful to compute the aggregate stock of credit to the private sector, which is given by the sum of the loans in pesos and in dollars granted by each bank:

$$
l_{t}^{A} \equiv \int_{0}^{n^{*}}[1-\alpha(1-\bar{E} / E)] l d x=[1-\alpha(1-\bar{E} / E)] n^{*} l .
$$




\subsection{Government}

The government in this economy is a benevolent planner that combines both the fiscal and the monetary authority. From a pure monetary point of view, it holds international reserves and domestic credit, and it also prints money. Thus, the balance-sheet for the monetary authority in real terms is:

$$
h_{t}+D_{t} / E_{t}=m_{t}^{s},
$$

where $h_{t}$ is the stock of international reserves, $D_{t}$ is the nominal domestic credit extended by the monetary authority, $E_{t}$ is the nominal exchange rate, and $m_{t}^{s}$ is the real money supply.

The government receives a return on the stock of international reserves, obtains some revenues from money creation and gives lump-sum transfers to the household. The flow constraint of the government is:

$$
\dot{h}=r h_{t}+\dot{m}+\varepsilon_{t} m_{t}-\bar{\tau},
$$

where $\dot{h}$ is the instantaneous change in the stock of international reserves and $\dot{m}$ is the instantaneous change in the stock of real balances.

It is assumed that transfers are exogenously given. This means that the government cannot change them at any moment to balance the fiscal accounts, except at $t=0$. Once transfers are initially set, there are no more non-distortionary instruments to balance the fiscal budget. This assumption will prove to be key in deriving the results of the model.

The intertemporal resource constraint for the whole government is obtained integrating equation (28) forward, and it is equal to:

$$
h_{0}+\int_{0}^{\infty}\left(\dot{m}+\varepsilon_{t} m_{t}\right) e^{-r t} d t=\bar{\tau} / r,
$$

where $h_{0}$ is the initial stock of international reserves.

\subsection{Initial steady state}


Consider the following three assumptions to define the initial steady state of this economy. First, the government determine the nominal exchange rate to be:

$$
E_{t}=\bar{E} .
$$

Second, the initial stock of reserves is equal to zero. This is assumed just for simplicity, otherwise the central bank would make nominal profits or losses when a discrete depreciation or appreciation occurs, which would not change the results of the model:

$$
h_{0}=0 .
$$

Finally, it is assumed that the transfers are set equal to the return obtained from the international reserves, that means they are equal to zero:

$$
\bar{\tau}=0 .
$$

Given those assumptions, the equilibrium inflation rate would be zero:

$$
\varepsilon^{*}=0 .
$$

Therefore, the household's consumption rule is given by:

$$
c=r a_{0}+\frac{1}{2} r l-r m(r)-v[m(r)] .
$$

\section{A monetary shock}

This section deals with the optimal policy that the government should implement when the economy faces an unexpected reduction in the demand of money.

\subsection{Overview of the problem}

To grasp intuition on the policy menu available to the government, it will help to focus the attention on the equilibrium condition in the money market.

$$
m_{t}^{d}=h_{t}+D_{t} / E_{t} .
$$

When real money demand is reduced, real money supply should decrease accordingly, to clear the money market. There are three instruments available to the policymakers to perform this task: 
(i) reduce reserves

(ii) increase the nominal exchange rate

(iii) reduce nominal domestic credit

It is assumed that the third choice is not available to the government. ${ }^{18}$ Therefore, the policymaker would have to choose the optimal amount of reserves to sell in the foreign exchange market and the optimal depreciation rate, subject to the constraint that the money market clears.

\subsubsection{Stable exchange rate: The monetary effect}

Suppose that the policymaker decides to use all the reserves that were necessary to absorb the fall in money demand (that is $\Delta h=\Delta m$ ), keeping the nominal exchange rate stable at the initial value. Under this response, given the government budget constraint, intervention has to be financed through inflation.

Then, the optimal consumption path that the household will follow is:

$$
c^{\text {stable }}=r a_{0}+\frac{1}{2} r l-i \tilde{m}(i)-v[\tilde{m}(i)]
$$

where $\tilde{m}$ (.) is the money demand after the shock.

Equation (33) shows the "monetary effect" generated by the intervention. Consumption is lower when the nominal exchange rate is kept stable, because the higher nominal interest rate leads to a lower demand for money, and therefore, to higher transaction costs.

\subsubsection{Floating exchange rate: The output effect}

\footnotetext{
18 In fact, reducing the stock of domestic credit will be equivalent to reduce the stock of international reserves.

Ruling out the existence of a helicopter drop in this economy, there are no other ways to reduce domestic credit than by cutting funds to the treasury. The central bank could not engage in open market operations with public bonds, because there is no demand for this kind of assets; and it could not adjust the credit to the banking system (i.e. rediscounts) because it does not exist in the model, either. Thus, the fiscal authority would have to reduce valuable expenditure or raise funds through a distortionary tax, which are the alternatives available when the governement as a whole loses reserves.

There also exist other alternatives. The treasury could finance the same level of expenditure making a swap of domestic credit by international reserves, or domestic credit by international credit. In both cases, the net stock of international assets would be reduced and therefore, all the considerations mentioned for the reserves reduction would be applied.
} 
Suppose now that the policymaker decides to leave the nominal exchange rate to fully adjust, keeping the stock of reserves, and thus inflation tax, unchanged (that means $\Delta h=\varepsilon=0$ ). In this case, the financial system would be undermined, given its exposure to nominal depreciations.

Then, the optimal consumption path will be:

$$
c^{\text {float }}=r a_{0}+\frac{1}{2} r\left(n^{*}\right)^{2} l-r \widetilde{m}(r)-v[\widetilde{m}(r)] .
$$

Equation (34) shows the "output effect" generated by the contraction of the banking system. Consumption is lower after the increase in the nominal exchange rate, because there is an output loss driven by the reduction in aggregate credit; which arises when the financial sector is scaled down by the depreciation.

\subsubsection{To stabilize or to float?}

Having described the two polar choices, the election of one of them is given by the comparison between the level of consumption, and hence welfare, that they give. The results are straightforward, if consumption under full intervention $\left(c^{\text {stable }}\right)$ is bigger than consumption under non-intervention $\left(c^{\text {float }}\right)$, then the optimal choice will be to keep the nominal exchange rate stable; and if it is smaller it should be allowed the exchange rate to freely float.

Obviously, these are two extreme cases. There is also something between them, which would represent the case of partial intervention. To obtain that intermediate case it would be useful to formally set the problem.

\subsection{Optimal policy response}

Given its budget constraint, the benevolent government should choose its policy instruments, the discrete depreciation rate $\hat{E}$, and the inflation rate $\varepsilon$, such that they maximize the household's welfare, $U$, and that all the markets clear (credit markets, money market, and goods market).

The problem is then, 


$$
\underset{\hat{E}, \varepsilon}{\operatorname{Max}} U=\int_{0}^{\infty} \log \left(c_{t}\right) e^{-\beta t} d t
$$

subject to:

$$
\begin{aligned}
& c=r a_{0}+\frac{1}{2} r\left(n^{*}\right)^{2} l-(r+\varepsilon) \tilde{m}(r+\varepsilon)-v[\tilde{m}(r+\varepsilon)] \\
& \hat{E}=\frac{E-\bar{E}}{\bar{E}} \\
& n^{*}=\frac{1+\hat{E}(1-\alpha)}{1+\hat{E}} \\
& r \Delta h=-\varepsilon \tilde{m}(r+\varepsilon) \\
& \Delta h=\Delta m+\hat{E} m_{0} .
\end{aligned}
$$

The constraint (36) is the household's consumption rule as a function of the government's policy instruments, which permits to express the welfare function as the indirect utility function of the household, and therefore allows the government to choose directly the policy instruments. Equation (37) is the discrete depreciation rate. Equation (38) is the efficiency of the marginal bank as a function of the depreciation rate. The constraint (39) comes from the government's flow constraint. Finally, the constraint (40), comes from the money market clearing condition. ${ }^{19}$

The FOCs of the problem are:

$$
\begin{aligned}
& \hat{E}:-\frac{1}{c}\left\{r l[1+\hat{E}(1-\alpha)] \alpha(1+\hat{E})^{-3}\right\}+\xi m_{0} r \leq 0 \\
& \varepsilon:-\frac{1}{c}\left[\tilde{m}(r+\varepsilon)+(r+\varepsilon) \tilde{m}^{\prime}+v^{\prime} \tilde{m}^{\prime}\right]+\xi\left[\tilde{m}(r+\varepsilon)+\varepsilon \widetilde{m}^{\prime}\right] \leq 0,
\end{aligned}
$$

where $\xi$ is the Lagrange multiplier associated to the government's budget constraint.

To solve this problem, three different cases could be considered: ${ }^{20}$

i) $\hat{E}=0, \varepsilon>0$ (full intervention)

ii) $\hat{E}>0, \varepsilon=0$ (no intervention)

iii) $\hat{E}>0, \varepsilon>0$ (partial intervention).

\footnotetext{
${ }^{19}$ The credit market clearing condition is already included in restriction (36).

${ }^{20}$ In the non-distorted economy, the choice between the two policy instrument is indeterminate. When the government has the possibility of raising lump-sum taxes ( $\tau$ is not given anymore), it would be able to optimally finance the intervention without introducing any distortion into the economy. When the currency mismatch is inexistent $(\theta=1)$, changes in the nominal exchange rate are completely harmless, and the government could leave the nominal exchange rate depreciates after the shock without any social loss.
} 
Figure 2 gives an intuitive picture of the set of policies from where the government can choose.

\subsection{Results}

Depending on the parameters, the optimal policy response is one of the following three prescriptions.

\subsubsection{Full intervention}

In the full-intervention case, the nominal exchange rate is maintained in its original level; nevertheless, to finance the intervention it would be necessary to generate some inflation.

Proposition 1 (Stabilize) When there are not non-distortionary taxes available and the economy is exposed to currency depreciations, the nominal exchange rate will be kept stable if the elasticity of money demand is below a threshold, $\in$, and the currency mismatch is above a threshold, $\bar{\alpha}$.

\section{Proof See Appendix}

This implies that when the "output effect" is greater than the "monetary effect" it would be better to avoid depreciations. On one hand, the output effect will be big when depreciations are very costly, which suggests that the economy has to be exposed to a big currency mismatch. On the other hand, the monetary effect will be small when inflation is not very distortionary, and that requires an inelastic money demand.

\subsubsection{No intervention}

In the non-intervention case, the stock of reserves and therefore the inflation rate, will not change; but the exchange rate will fully depreciate. 
Proposition 2 (Pure Floating) When there are not non-distortionary taxes available and the economy is exposed to currency depreciations, the exchange rate will fully depreciate if the currency mismatch is below a threshold, $\alpha$.

Proof See Appendix

In this case, when the "monetary effect" is greater than the "output effect", it is worthwhile to leave the currency fully depreciates, avoiding any inflation. The equilibrium in the money market is restored through a price adjustment, the price of the domestic currency will be such that the money market clears.

Interestingly, if the economy is perfectly hedged, $\alpha=0$, the nominal exchange rate will be fully depreciated.

\subsubsection{Partial intervention}

When the government partially intervenes, there would be both, a depreciation of the exchange rate and some inflation.

Proposition 3 (Dirty Floating) When the parameters of the economy are such that the optimal policy is partial intervention, the exchange rate will be strongly defended when the currency mismatch is wide, the money demand elasticity is low and the financial system is large.

Proof See Appendix

Intuitively, a wide currency mismatch makes an unexpected depreciation more costly, hence the government will save resources buffering the jump of the nominal exchange rate through more intervention. An inelastic money demand allows the government to rely heavily on inflation as the source of funds for intervention, since it would not distort the allocation of money too much. Finally, a large financial system, in terms of its lending capacity, means that the credit crunch would be greater when an unexpected depreciation forces some banks to go bankrupt.

Figures 3 and 4 depict the policy rule, that means how much inflation should be generated to finance the intervention, under different circumstances. 
Figure 3 shows the inflation rate as a function of the currency mismatch, for different values of the elasticity of money demand, keeping constant the magnitude of the shock. For low values of the currency mismatch the optimal response is not intervene, and therefore generates zero inflation. The amount of intervention is rising with the mismatch, until a point in which is optimal to generate enough inflation to keep the exchange rate at the initial value. For a higher elasticity, the policy rule moves upward and to the right. In this case, the degree of intervention and the inflation rate are lower for each level of the currency mismatch, when this variable is not too large. However, for large values of $\alpha$, the inflation rate will end up being higher.

Figure 4 presents the inflation rate as a function of the elasticity of money demand for different values of the currency mismatch, keeping again the magnitude of the shock constant. ${ }^{21}$ When the elasticity is low, the policymaker will use all the inflation necessary to finance the intervention, which will start to decrease for values of elasticities above a threshold. For a larger currency mismatch, the policy rule moves to the right. This implies that the range of elasticities for which full intervention is optimal will be wider. Moreover, inflation and the amount of intervention will be higher for each elasticity value.

\section{Conclusion}

Many papers document the fact that emerging economies intervene more heavily in the exchange rate market than the developed countries. This paper provides a model to explain this behavior. It relies on two facts about emerging markets: they face fiscal restrictions during turbulent times and they have a mismatch in the currency denomination of their assets and liabilities. These two features make both interventions and depreciations costly; as a result, policymakers have to choose the optimal policy mix, in order to minimize costs.

\footnotetext{
${ }^{21}$ This picture corresponds to the case where the necessary condition for a pure floating is not satisfied, this means: $\alpha l / m_{0}>1$.
} 
If the government chooses to intervene, it faces fiscal constraints as it will need to raise additional resources or cut expenditures. However, reducing public expenditure is not an easy task in emerging markets. And also, the availability of non-distortionary instruments is utopian, even in developed countries. Therefore, the inflation tax becomes an effective instrument to collect resources, which would distort the allocation of real balances and may have some real effects on the economy.

This observation of a constrained public sector has many other implications. For instance, it points towards the explanation of the fact that developing countries hold a high stock of international reserves, as is analyzed in Aizenman and Marion (2002).

On the other hand, if the government chooses to depreciate, it faces the harmful effects of a currency mismatch. If liabilities in foreign currency are greater than assets in foreign currency, a reduction in the value of the domestic currency would imply a resource loss for the country. The paper takes the currency mismatch as given, and then explains how the resource loss is generated by a depreciation. It would be fruitful to go one step backward, and make endogenous the decision of being exposed to exchange rate risk.

Some institutional factors could be the origin of the lack of hedging in emerging markets. Identifying these factors would be a prerequisite for finding the policy measures necessary to get rid of the exchange rate risk, and therefore to reduce the costs of depreciations. When modelling currency mismatch, the benefits of being unhedged should be compared to the costs. Of the latter, the output cost, generated through the banking channel outlined here, should play a primary role.

Based on intervention and depreciation costs, this paper is able to rationalize the fact that emerging markets end up with higher inflation rates and lower fluctuations in the nominal exchange rate as the outcome of an optimal policy decision. The results imply that countries with highly elastic money demand would refrain from intervening too much in the foreign exchange market if they are not able to undertake a fiscal adjustment. For them, it would be better to raise revenues with an unexpected depreciation rather than relying on a perfectly anticipated future inflation tax. On the other hand, countries with a high degree of currency mismatch would play tough to stabilize the value of the currency, even at expense of a higher future inflation. 


\section{Appendix}

Proposition 1 - Proof The economy is in the full intervention corner when:

$$
\begin{aligned}
& \hat{E}=0 \\
& \varepsilon>0 .
\end{aligned}
$$

Imposing these conditions and the complementary slackness conditions to (41) and (42) the following inequality is obtained:

$$
\frac{\alpha l}{m_{0}}>\frac{\tilde{m}(r+\varepsilon)+(r+\varepsilon) \tilde{m}^{\prime}+v^{\prime} \tilde{m}^{\prime}}{\tilde{m}(r+\varepsilon)+\varepsilon \tilde{m}^{\prime}} .
$$

The LHS of equation (43) is determined by the exogenous parameters.

On the other side, using equation (10) the RHS can be written as:

$$
R H S=\frac{\tilde{m}(r+\varepsilon)}{\widetilde{m}(r+\varepsilon)+\varepsilon \tilde{m}^{\prime}},
$$

or, defining the elasticity of money demand as:

$$
\in_{m, i} \equiv-m^{\prime}(r+\varepsilon) / m,
$$

it can be expressed in the following way:

$$
R H S=\frac{1}{1-\epsilon_{m, i} \varepsilon /(r+\varepsilon)},
$$

which are both functions of $\varepsilon$. In turn, using equations (39) and (40) $\varepsilon$ can be expressed as a function of the monetary shock, $\Delta m$, and therefore the RHS of equation (43) is just a function of $\Delta m$.

Depending on the functional form of $v(m)$, and in turn of $m(i)$, the RHS could be a nonmonotonic function of $\Delta m$. To simplify the proof, it will be analyzed just the case of a money demand with constant elasticity, which gives a monotonic RHS. ${ }^{22}$

Then,

$$
\begin{aligned}
& \lim _{\Delta m \rightarrow 0} R H S=1 \\
& \operatorname{slope}(R H S) \equiv \frac{d R H S}{d \Delta m}=\frac{d R H S}{d \varepsilon} \frac{d \varepsilon}{d \Delta m}<0 \\
& \frac{d \operatorname{slope}(\text { RHS })}{d \in_{m, i}}<0 .
\end{aligned}
$$

\footnotetext{
${ }^{22}$ A lineal money demand will also give a monotonic RHS.
} 
Figure 5 is constructed using these conditions, and it shows that:

(i) A necessary condition for full intervention is:

$$
\alpha l / m_{0}>1 ; \quad \forall \in_{m, i} \neq 0 .
$$

(ii) Given $\alpha$ and $\in_{m, i} \neq 0$, full intervention will be optimal for values of $\Delta m$ below a threshold.

(iii) Given $\alpha$ and $\Delta m$, full intervention will be optimal for values of $\epsilon_{m, i}$ small enough.

Proposition 2 - Proof The economy is in the non-intervention corner when:

$$
\begin{aligned}
& \hat{E}>0 \\
& \varepsilon=0 .
\end{aligned}
$$

Imposing those requirements to (41) and (42), and using the complementary slackness condition, the following inequality arises:

$$
\frac{\tilde{m}(r)+r \tilde{m}^{\prime}+v^{\prime} \tilde{m}^{\prime}}{\tilde{m}(r)}>\frac{\alpha l}{m_{0}}+\hat{E}(1-\alpha)(1+\hat{E})^{-3} .
$$

Using equation (10) the LHS of (47) is:

$$
L H S=1 .
$$

On the other side, in the non-intervention corner equation (40) becomes:

$$
\hat{E}=-\Delta m / m_{0}
$$

and thus, the RHS of (47) can be written as a function of $\Delta m$ and the exogenous parameters.

Then,

$$
\begin{aligned}
& \lim _{\Delta m \rightarrow 0} R H S=\lim _{\Delta m \rightarrow \infty} R H S=\alpha l / m_{0} \\
& \operatorname{slope}(R H S) \equiv \frac{d R H S}{d \Delta m}=\frac{d R H S}{d \hat{E}} \frac{d \hat{E}}{d \Delta m}\left\{\begin{array}{l}
<0 \text { for } \hat{\mathrm{E}} \in(0,1 / 2) \\
>0 \text { for } \hat{\mathrm{E}} \in(1 / 2, \infty)
\end{array} .\right.
\end{aligned}
$$

Figure 6 is constructed using these conditions, and it shows that:

(i) A necessary condition for no intervention is:

$$
\alpha l / m_{0}<1 .
$$

(ii) Given $\alpha$, no intervention will be the optimal response for values of $\Delta m$ below a lower threshold or above an upper threshold. 
Proposition 3 - Proof The interior solution is characterized by:

$$
\begin{aligned}
& \hat{E}>0 \\
& \varepsilon=0 .
\end{aligned}
$$

Taking into account those restrictions, equation (10) and the complementary slackness conditions, the FOCs could be expressed in the following way:

$$
\frac{\alpha l}{m_{0}}+\hat{E}(1-\alpha)(1+\hat{E})^{-3}=\frac{\widetilde{m}(r+\varepsilon)}{\widetilde{m}(r+\varepsilon)+\varepsilon \widetilde{m}^{\prime}} .
$$

Using equations (39) and (40) to replace $\hat{E}$ into (48), it is obtained one equation in just one variable, $\varepsilon$.

$$
F=\frac{\alpha l}{m_{0}}+(1-\alpha) \frac{\hat{E}_{(\varepsilon, \Delta m)}}{\left(1+\hat{E}_{(\varepsilon, \Delta m)}\right)^{3}}-\frac{\widetilde{m}(r+\varepsilon)}{\widetilde{m}(r+\varepsilon)+\varepsilon \widetilde{m}^{\prime}}=0 .
$$

Given that all the functions are invertible in terms of $\varepsilon$, equation (49) can be solved for $\varepsilon$ as a function of the parameters. Thus, relying on the implicit function theorem:

$$
\varepsilon=\varepsilon\left(\alpha, l / m_{0}, \in_{m, i}, \Delta m\right),
$$

where:

$$
\begin{aligned}
& \varepsilon_{\alpha}, \varepsilon_{l / m_{0}}>0 \\
& \varepsilon_{\epsilon_{m, i}}, \varepsilon_{\Delta m}<0 .
\end{aligned}
$$




\section{Tables and Figures}

Table 1: The backstage of interventions (average 1980-2000)

\begin{tabular}{lcccccc}
\hline & $\sigma_{\mathrm{E}} / \sigma_{\mathrm{h}}$ & $\begin{array}{c}\text { Monthly } \\
\text { inflation }\end{array}$ & $\theta$ & L/GDP & M/GDP & L/M \\
\hline Argentina & 0.70 & 7.1 & 4.1 & 0.25 & 0.05 & 5.4 \\
Bolivia & 0.03 & 0.9 & 2.9 & 0.30 & 0.07 & 4.3 \\
Brazil & 1.32 & 10.7 & 1.9 & 0.34 & 0.05 & 7.6 \\
Chile & 0.90 & 1.2 & 2.8 & 0.66 & 0.07 & 9.0 \\
Colombia & 0.27 & 1.7 & 3.8 & 0.20 & 0.09 & 2.2 \\
Indonesia & 0.90 & 0.9 & 0.7 & 0.33 & 0.10 & 3.4 \\
Korea & 0.45 & 0.5 & 1.6 & 0.54 & 0.08 & 6.7 \\
Malaysia & 0.43 & 0.3 & 1.8 & 0.76 & 0.21 & 3.6 \\
Mexico & 0.51 & 2.8 & 0.3 & 0.25 & 0.07 & 3.7 \\
Peru & 1.15 & 6.8 & 1.0 & 0.13 & 0.07 & 1.9 \\
Philippines & 0.19 & 0.9 & 1.3 & 0.38 & 0.08 & 4.9 \\
Thailand & 0.57 & 0.4 & 2.2 & 0.75 & 0.09 & 8.4 \\
Turkey & 0.39 & 4.1 & 0.7 & 0.22 & 0.05 & 4.6 \\
Uruguay & 0.27 & 3.2 & 0.5 & 0.40 & 0.05 & 7.5 \\
Venezuela & 0.63 & 2.9 & 0.3 & 0.23 & 0.13 & 1.8 \\
& & & & & & \\
Average Emerging Markets & 0.58 & 3.0 & 1.7 & 0.38 & 0.08 & 5.0 \\
Japan & & & & & & \\
USA & 0.85 & 0.1 & 1.3 & 1.22 & 0.30 & 4.1 \\
& 0.84 & 0.3 & 2.0 & 0.78 & 0.20 & 3.9 \\
\hline & & & & & & \\
\hline
\end{tabular}

Source: Own calculations, with data from the IFS for the period 1980-2000.

$\sigma_{\mathrm{E}}$ : Standard deviation of the monthly change in the nominal exchange rate.

$\sigma_{\mathrm{h}}$ : Standard deviation of the monthly change in international reserves.

$\theta=$ Liabilities in foreign currency/Assets in foreign currency ; for the financial system.

L: Stock of banking credit to domestic agents. M: Stock of nominal balances (M1).

GDP: Gross Domestic Product. 
Table 2: Determinants of nominal exchange rate variability

Dependent variable: $\quad$ Percentage change in the exchange rate per unit of percentage change in reserves

(Monthly changes)

Sample: $\quad 15$ emerging markets

Annual averages for the period 1980-2000

No fixed effects

\begin{tabular}{|c|c|c|c|c|c|c|c|}
\hline & $(1)$ & $(2)$ & (3) & (4) & $(5)$ & (6) & (7) \\
\hline \multirow[t]{2}{*}{ Constant } & $0.86 * * *$ & $3.11 *$ & $1.56^{*}$ & $3.93^{*}$ & $3.08 *$ & $2.84 *$ & $3.36^{*}$ \\
\hline & $(0.49)$ & $(0.87)$ & $(0.64)$ & $(1.00)$ & $(0.87)$ & $(0.89)$ & $(0.91)$ \\
\hline \multirow[t]{2}{*}{ Currency Mismatch } & $-0.530 * *$ & $-0.376^{* * *}$ & $-0.490 * *$ & $-0.344 * * *$ & $-0.367 * *$ & $-0.397 * *$ & $-0.384 * * *$ \\
\hline & $(0.258)$ & $(0.196)$ & $(0.243)$ & $(0.193)$ & $(0.196)$ & $(0.191)$ & $(0.193)$ \\
\hline \multirow[t]{2}{*}{ Fiscal Surplus / GDP } & $-17.31 * *$ & $-19.45^{*}$ & $-18.26^{* *}$ & $-20.34^{*}$ & $-19.53 *$ & $-19.80 *$ & $-19.23^{*}$ \\
\hline & $(8.92)$ & (8.03) & $(8.72)$ & $(7.85)$ & $(8.02)$ & $(7.84)$ & $(7.88)$ \\
\hline \multirow[t]{2}{*}{ Inflation $(-1)$} & 0.103 & $0.139 * * *$ & & & $0.139 * *$ & $0.133 * *$ & $0.134 * * *$ \\
\hline & $(0.078)$ & $(0.074)$ & & & $(0.074)$ & $(0.073)$ & $(0.074)$ \\
\hline \multirow[t]{2}{*}{ Monetization } & & & -4.11 & -7.12 & & & \\
\hline & & & $(5.58)$ & $(5.75)$ & & & \\
\hline \multirow[t]{2}{*}{ Growth $(-1)$} & -2.57 & -1.91 & -5.78 & -5.97 & -1.89 & -0.92 & -1.19 \\
\hline & $(5.13)$ & $(4.77)$ & $(4.86)$ & $(4.36)$ & $(4.77)$ & (4.94) & (4.97) \\
\hline \multirow[t]{2}{*}{ Lending } & $-0.001 * *$ & $-0.002 *$ & $-0.001 * *$ & $-0.002 *$ & & $-0.002 * *$ & $-0.002 * *$ \\
\hline & $(0.0005)$ & $(0.0006)$ & $(0.0005)$ & $(0.0005)$ & & (0.0008) & (0.0007) \\
\hline \multirow[t]{2}{*}{$\mathrm{CM}^{*}$ Lending } & & & & & $-0.001 * *$ & & \\
\hline & & & & & $(0.0007)$ & & \\
\hline \multirow[t]{2}{*}{ RER } & & $-2.41 *$ & & $-2.15^{*}$ & $-2.41 *$ & $-2.50 *$ & $-2.47 *$ \\
\hline & & $(0.76)$ & & $(0.66)$ & $(0.76)$ & $(0.76)$ & $(0.76)$ \\
\hline \multirow[t]{2}{*}{ Latin America } & & & & & & 0.632 & \\
\hline & & & & & & $(0.471)$ & \\
\hline \multirow[t]{2}{*}{ East Asia } & & & & & & & -0.502 \\
\hline & & & & & & & $(0.471)$ \\
\hline $\mathrm{R}^{2}$ & 0.11 & 0.18 & 0.09 & 0.14 & 0.18 & 0.18 & 0.18 \\
\hline N. Obs. & 285 & 285 & 285 & 285 & 285 & 285 & 285 \\
\hline
\end{tabular}

Newey-West standard errors are in parentheses.

*,**,***: 99\%, 95\%, 90\% significance level, respectively. 
Table 3: Determinants of nominal exchange rate variability

Percentage change in the exchange rate per unit of percentage change in Dependent variable: $\quad$ reserves

(Monthly changes)

Sample:

15 emerging markets

Annual averages for the period 1980-2000

Fixed effects included

\begin{tabular}{|c|c|c|c|c|c|}
\hline & (1) & (2) & (3) & (4) & $(5)$ \\
\hline \multirow[t]{2}{*}{ Constant } & -0.47 & $1.89 * * *$ & -1.44 & 1.38 & $1.86 * * *$ \\
\hline & $(0.95)$ & $(1.15)$ & $(1.72)$ & (1.99) & (1.15) \\
\hline \multirow[t]{2}{*}{ Currency Mismatch } & $-0.653^{*}$ & $-0.512 * *$ & $-0.632 *$ & $-0.504 * *$ & $-0.508 * *$ \\
\hline & $(0.218)$ & $(0.217)$ & $(0.220)$ & $(0.223)$ & $(0.218)$ \\
\hline \multirow[t]{2}{*}{ Fiscal Surplus / GDP } & $-18.28 *$ & $-19.54 *$ & $-19.17 *$ & $-19.24 *$ & $-19.61 *$ \\
\hline & (6.97) & $(6.84)$ & (7.18) & (7.18) & (6.84) \\
\hline \multirow[t]{2}{*}{ Inflation (-1) } & $0.103 *$ & $0.133^{*}$ & & & $0.133^{*}$ \\
\hline & $(0.042)$ & $(0.042)$ & & & $(0.042)$ \\
\hline \multirow[t]{2}{*}{ Monetization } & & & 9.24 & 2.52 & \\
\hline & & & (11.04) & (11.18) & \\
\hline \multirow[t]{2}{*}{ Growth $(-1)$} & -4.19 & -3.12 & $-7.46 * * *$ & $-7.08 * * *$ & -3.09 \\
\hline & (4.06) & (3.99) & (3.93) & $(3.89)$ & $(4.00)$ \\
\hline \multirow[t]{2}{*}{ Lending } & -0.001 & -0.002 & -0.001 & -0.001 & \\
\hline & $(0.002)$ & $(0.002)$ & $(0.002)$ & $(0.002)$ & \\
\hline \multirow[t]{2}{*}{$\mathrm{CM}^{*}$ Lending } & & & & & -0.001 \\
\hline & & & & & $(0.003)$ \\
\hline \multirow[t]{2}{*}{ RER } & & $-2.22 *$ & & $-1.77 *$ & $-2.19 *$ \\
\hline & & $(0.63)$ & & $(0.65)$ & $(0.63)$ \\
\hline $\mathrm{R}^{2}$ & 0.18 & 0.18 & 0.17 & 0.19 & 0.22 \\
\hline N. Obs. & 285 & 285 & 285 & 285 & 285 \\
\hline
\end{tabular}

Newey-West standard errors are in parentheses.

$*, * *, * * *$ : 99\%, 95\%, 90\% significance level, respectively. 
Figure 1: Floating exchange rate regimes.

Probability that the monthly change is in a $+/-2.5 \%$ band.

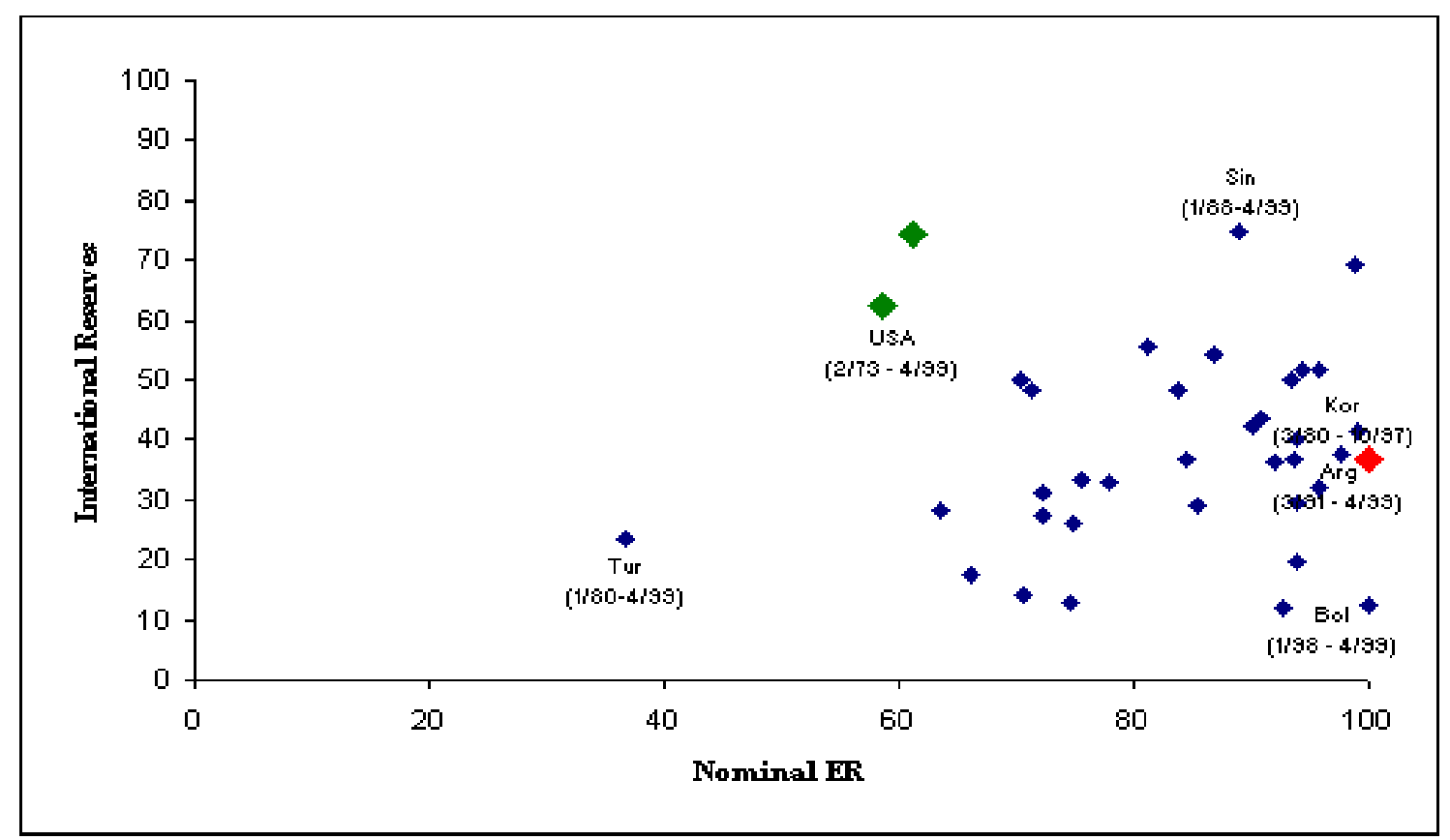

Source: Constructed with the results from Calvo, G. and C. Reinhart (2002).

Figure 2: The policy options.

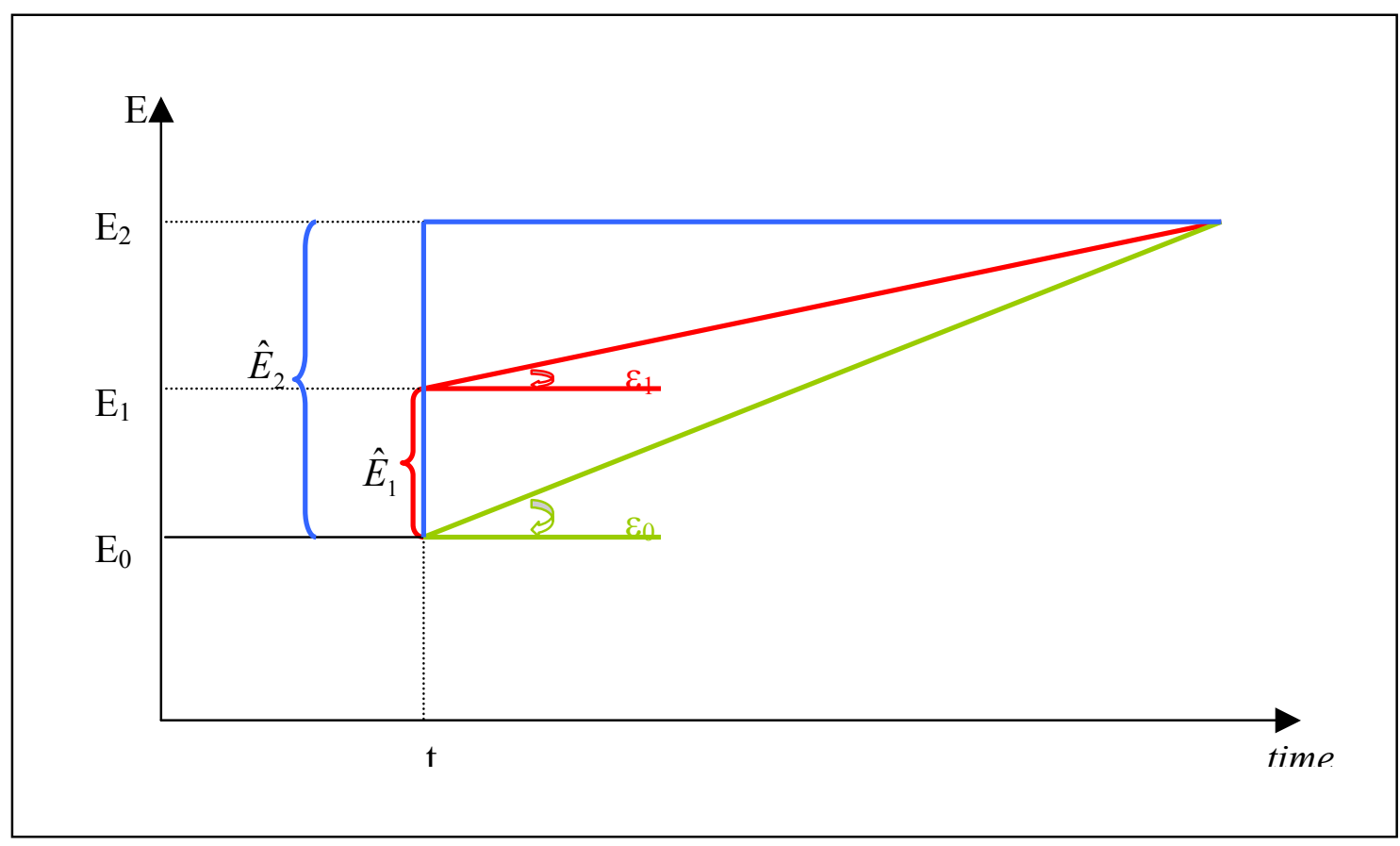


Figure 3: The policy rule: Intervention and the currency mismatch.

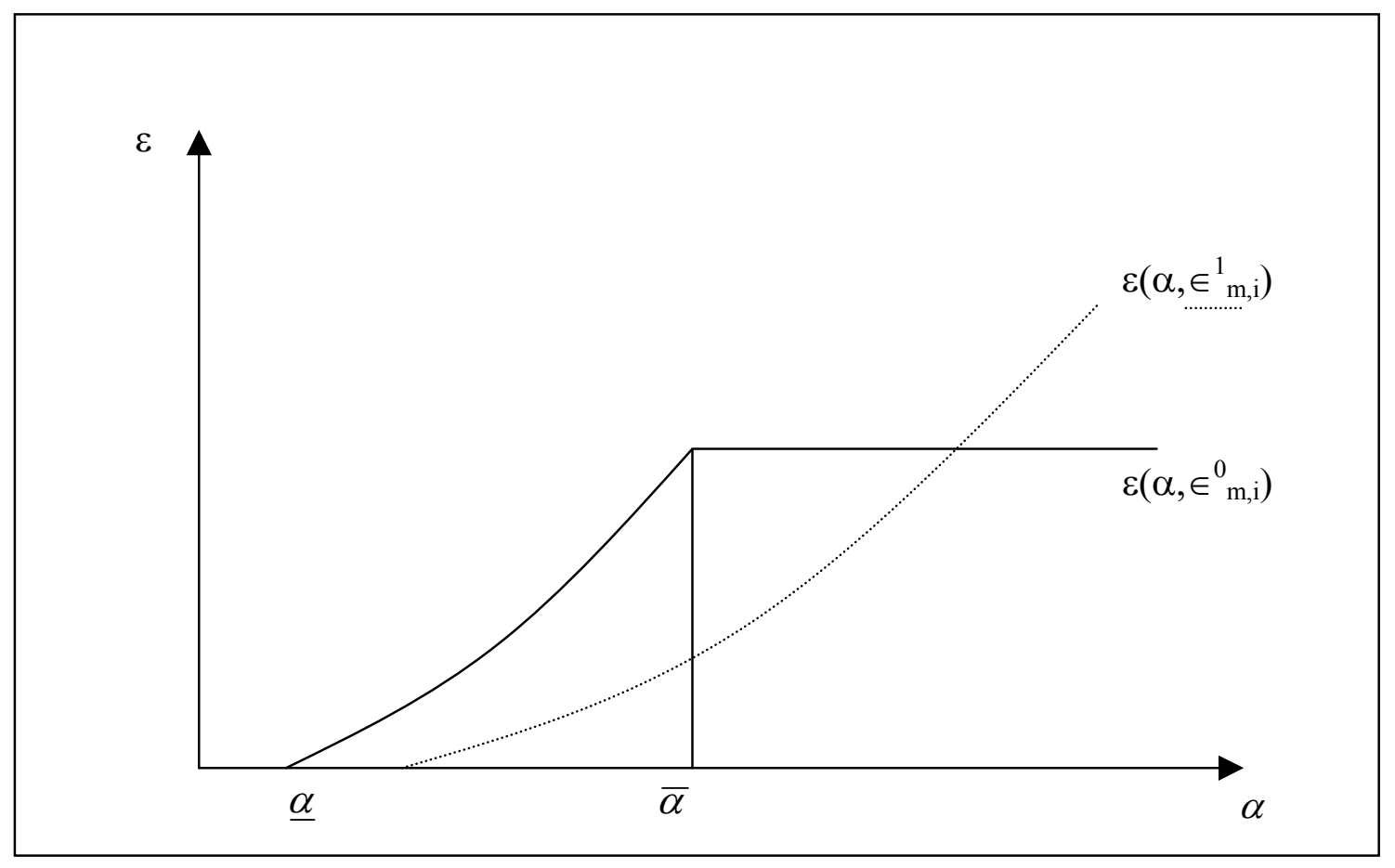

Figure 4: The policy rule: Intervention and the elasticity of money demand.

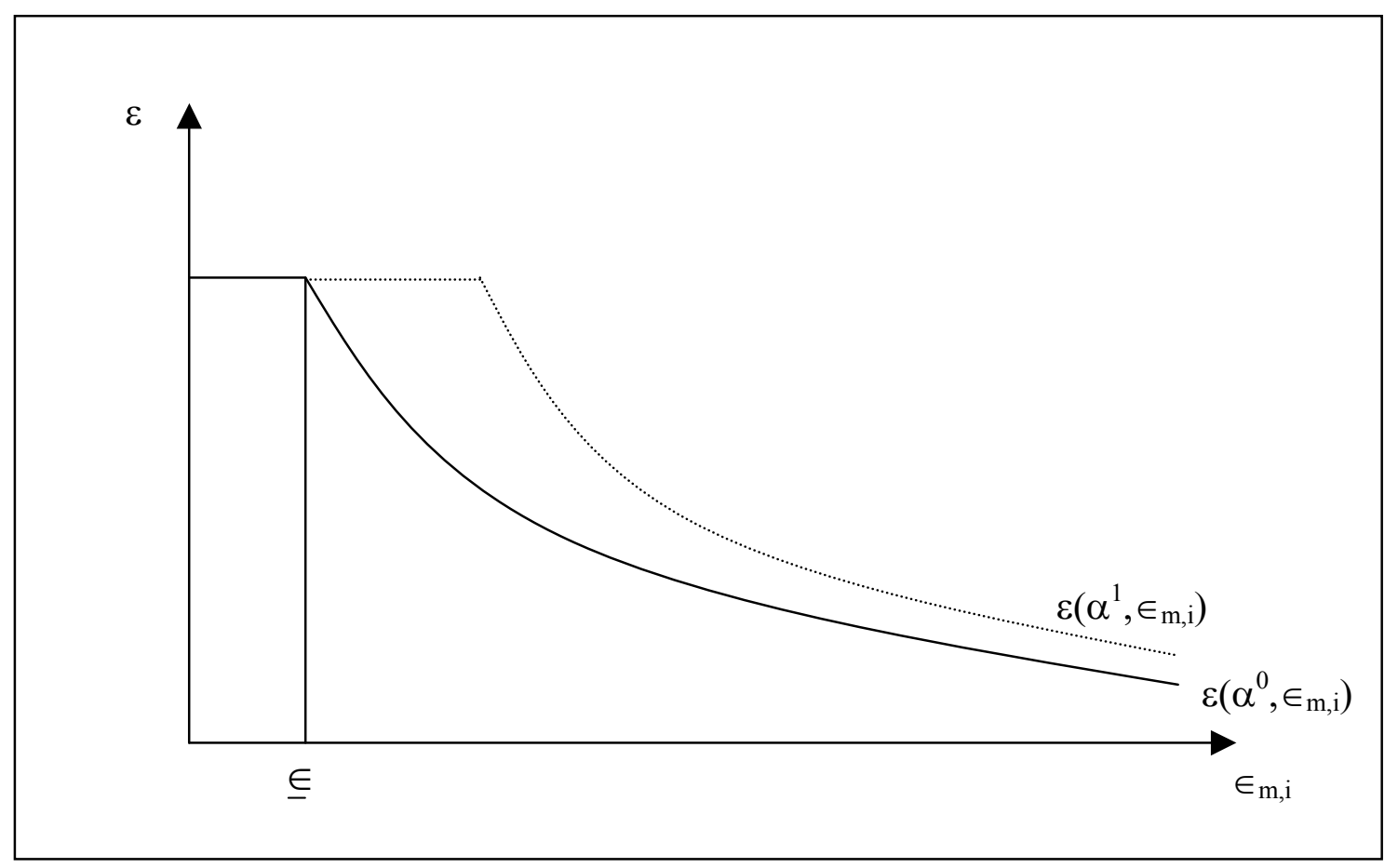


Figure 5: Full intervention.

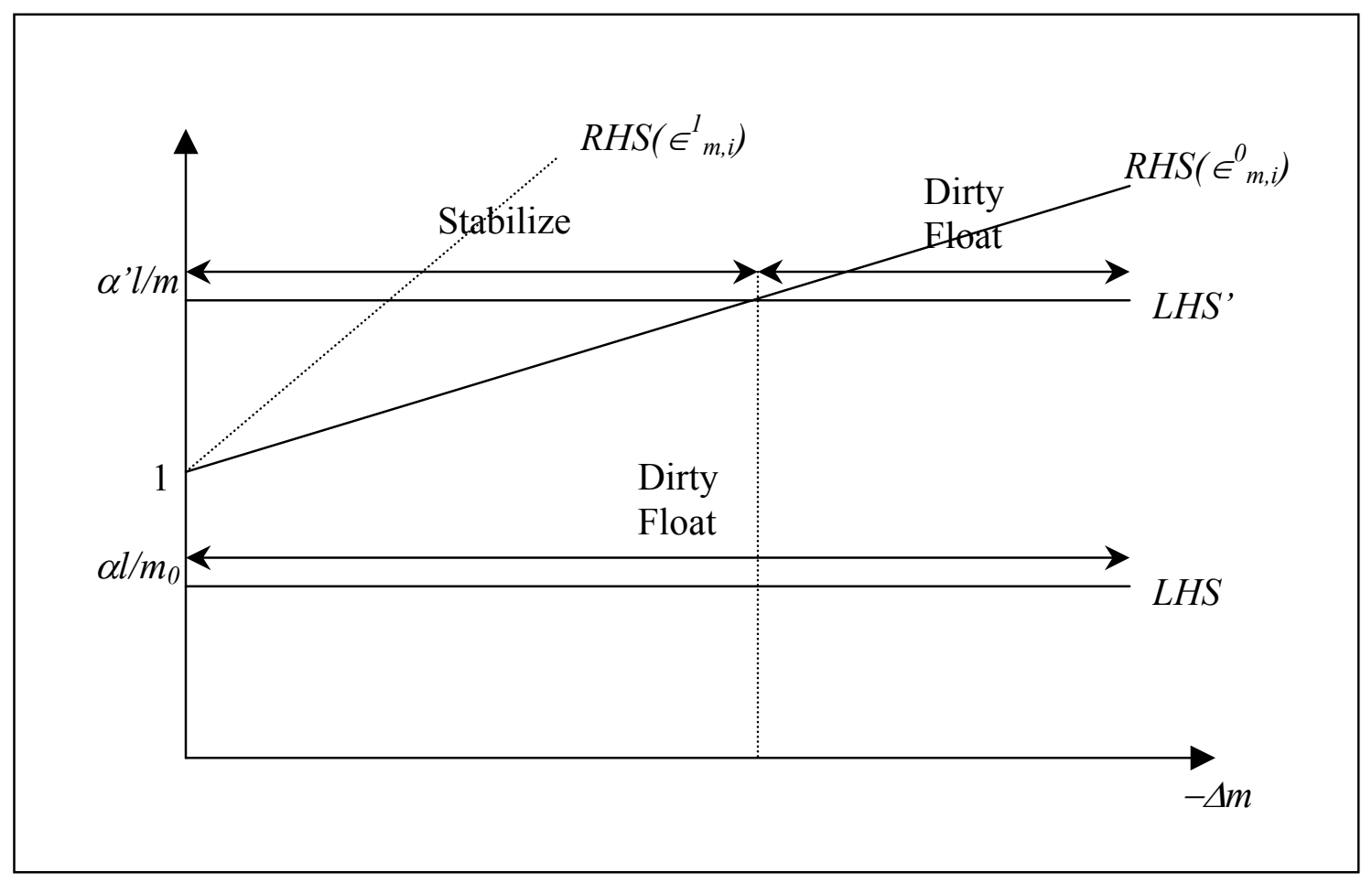

Figure 6: No intervention.

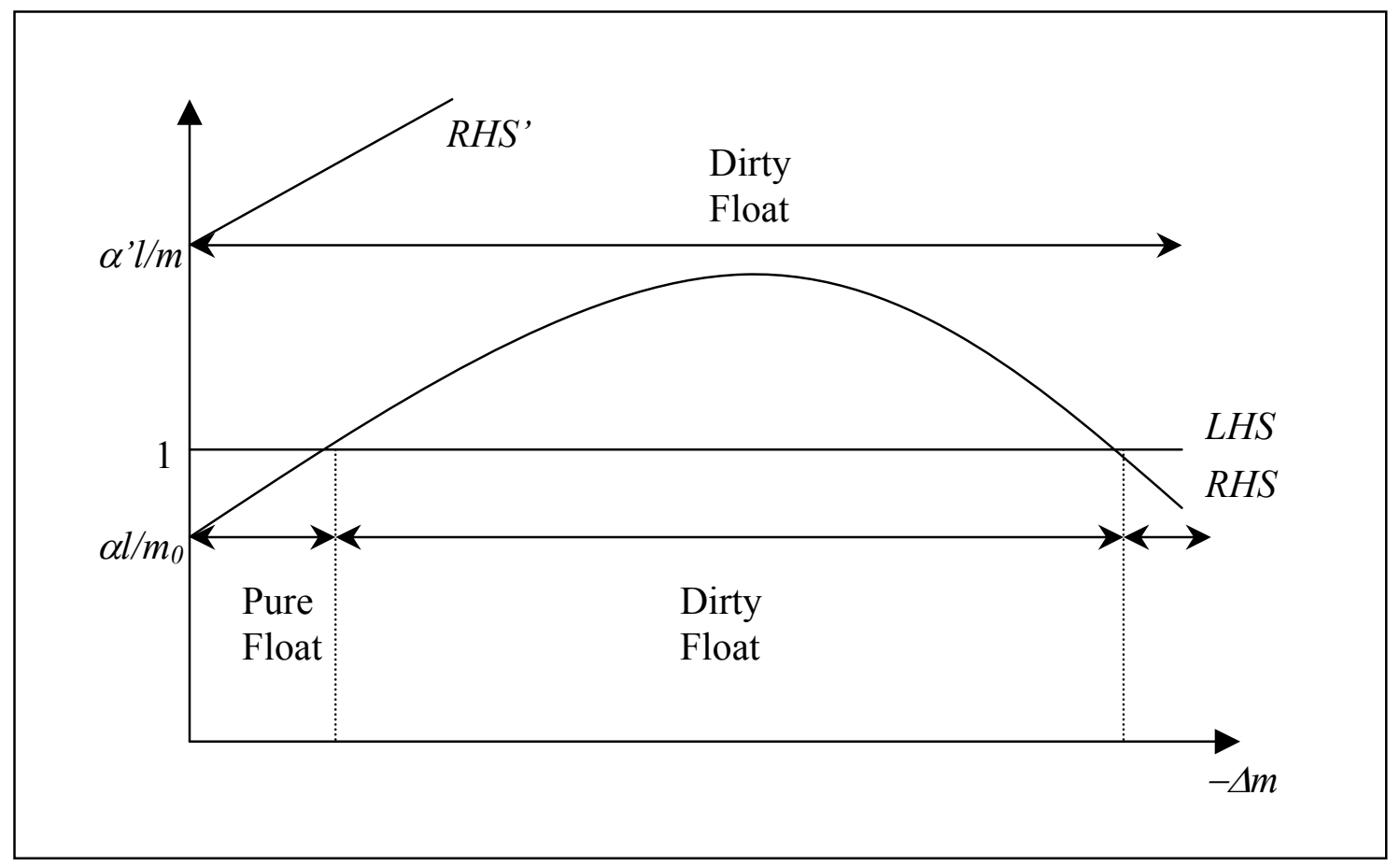




\section{References}

[1] Aghion, P., P. Bacchetta, and A. Banerjee (2000),"Currency Crises and Monetary Policy in an Economy with Credit Constraints", mimeo Harvard University.

[2] Aghion, P., P. Bacchetta, and A. Banerjee (2001),"A Corporate Balance-Sheet Approach to Currency Crises", Studienzentrum Gerzensee Working Paper No. 01.05.

[3] Aizenman, J. and N. Marion (2002), "International Reserve Holdings with Foreign Risk and Costly Tax Collection", mimeo UC Santa Cruz.

[4] Bernanke, B. and M. Gertler (1995), "Inside the Black Box: The Credit Channel of Monetary Policy Transmission", Journal of Economic Perspectives, 9, 27-48.

[5] Burnside, C., M. Eichenbaum, and S. Rebelo (1998), "Prospective Deficits and the Asian Currency Crisis", NBER Working Paper No. 6758.

[6] Burnside, C., M. Eichenbaum, and S. Rebelo (1999), "Hedging and Financial Fragility in Fixed Exchange Rate Regimes", NBER Working Paper No. 7143.

[7] Caballero, R. and A. Krishnamurthy (2001), "A "Vertical" Analysis of Crises and Intervention: Fear of Floating and Ex-Ante Problems", NBER Working Paper No. 8428.

[8] Calvo, G. and C. Reinhart (2000a), "Fear of Floating", mimeo University of Maryland.

[9] Calvo, G. and C. Reinhart (2000b), "Fixing for Your Life", NBER Working Paper No. 8006 .

[10] Céspedes, L., R. Chang, and A. Velasco (2001), "Balance Sheets and Exchange Rate Policy", mimeo Harvard University.

[11] Chamon, M. (2001), "Why Don't we Observe Foreign Lending to Developing Countries in their Currency, even when Indexation to Inflation is Available?", mimeo Harvard University.

[12] Eichengreen, B. and R. Hausmann (1999), "Exchange Rate and Financial Fragility", NBER Working Paper No. 7418.

[13] Frankel, J. (1999), "No Single Currency Regime is Right for All Countries or at All Times", NBER Working Paper No. 7338.

[14] Hausmann, R., U. Panizza, and E. Stein (2001), "Original Sin, Pass-through, and Fear of Floating", mimeo Kennedy School of Government, Harvard University. 
[15] Kaminsky, G. and C. Reinhart (1999), "The Twin Crises: The Causes of Banking and Balance-of-Payments Problems", American Economic Review, 89, 473-500.

[16] Krugman, P. (1999), "Balance Sheets, the Transfer Problem, and Financial Crises", mimeo MIT.

[17] Lahiri, A. and C. Végh (2001), "Living with the Fear of Floating: An Optimal Policy Perspective", NBER Working Paper No. 8391.

[18] Levy-Yeyati, E. and F. Sturzenegger (2002), "Classifying Exchange Rate Regimes: Deeds vs. Words", mimeo UTDT.

[19] Parrado, E. and A. Velasco (2002), "Optimal Interest Rate Policy in a Small Open Economy", NBER Working Paper No. 8721.

[20] Rebelo, S. and C. Végh (2001), "When Is it Optimal to Abandon a Fixed Exchange Rate?", mimeo Northwestern University and UCLA.

[21] Schneider, M. and A. Tornell (2000), "Balance Sheet Effects, Bailout Guarantees and Financial Crises", NBER Working Paper No. 8060. 